\title{
A novel process to recover sulfur in aqueous phase under ambient condition
}

\author{
Yu Huang ${ }^{1} \cdot$ Haoyi Chen ${ }^{1}$ Yongchun $\mathrm{Lu}^{1} \cdot$ Bonan $\mathrm{Liu}^{2} \cdot$ Huahong Shi ${ }^{1} \cdot$ \\ Tiancun Xiao ${ }^{1,2}$
}

Received: 9 January 2015 / Accepted: 24 March 2015/Published online: 4 April 2015

(C) The Author(s) 2015. This article is published with open access at Springerlink.com

\begin{abstract}
Sulfur recovery is an important industrial process for fossil fuel clean consumption, in which $\mathrm{H}_{2} \mathrm{~S}$ is firstly separated from the gas stream from the hydrodesulfurization process or gasified gas of coal or biomass. Meanwhile, almost equivalent half amount of $\mathrm{SO}_{2}$ is produced from the boiler on-site due to the power and steam generation or the fluid catalytic cracking process in a refinery. Currently, $\mathrm{H}_{2} \mathrm{~S}$ is converted into elemental sulfur using Claus process, which is being used worldwide, and $\mathrm{SO}_{2}$ is removed from the flue gas using lime or lime water. The two sulfur removal technologies require lots of capital investment and operating cost. Here, we have developed a novel process for $\mathrm{SO}_{2}$ in flue gas to react with $\mathrm{H}_{2} \mathrm{~S}$ from the gasified gas stream, to convert them elemental sulfur by washing the flue gas and $\mathrm{H}_{2} \mathrm{~S}$ with liquid catalyst containing water stream, the sulfur in $\mathrm{SO}_{2}$ and $\mathrm{H}_{2} \mathrm{~S}$ is converted into elemental sulfur and floated in the washed solution pool, which can be filtered out.

Here, the pilot test results of the aqueous phase ambient temperature sulfur recovery process has been described and analyzed. The system converted more than $1000 \mathrm{ppm}$ of $\mathrm{H}_{2} \mathrm{~S}$ and 500-600 ppm of $\mathrm{SO}_{2}$ in the flue gas into elemental sulfur in aqueous phase at temperature below $100{ }^{\circ} \mathrm{C}$. The flue gas was washed with our acid aqueous media, and the sulfur is formed in the aqueous acid catalyst solution and
\end{abstract}

Tiancun Xiao

xiao.tiancun@chem.ox.ac.uk;

http://www.boxenergytech.com

1 Guangzhou Boxenergytech Ltd, D-102 International Business Incubator, Guangzhou Development Zone, Guangzhou, People's Republic of China

2 Inorganic Chemistry Laboratory, Oxford University, South Parks Road, Oxford OX1 3QR, UK was filtered out. The sulfur powder has the same laser Raman spectra with the Claus process, with the main structure as $\mathrm{S}_{8}$ with high purity.

Keywords Sulfur recovery - Claus - Aqueous phase · Flue gas · Hydrogen sulfide

\section{Introduction}

Sulfur is one of the main pollutants from fossil fuel and mostly emitted to air in the form of $\mathrm{SO}_{2}$, and $99 \%$ of which in air comes from human sources. The main source of sulfur dioxide in the air is industrial activity that processes materials that contain sulfur, e.g., the generation of electricity from coal, oil, or gas that contains sulfur [1-4]. Directly combusting coal gives rise to not only $\mathrm{SO}_{2}$, but also dust and heavy metal pollutant. One of the main aims in oil refinery is to remove the sulfur in the crude oil and convert it into sulfur powder, which is a solid matter. Indeed, sulfur recovery process is becoming increasingly important with the increase of total fossil fuel consumption, thus a cleaner way to make use of fossil fuel and more effective way to recover sulfur are urgently needed.

For example, to make use of coal or bunker oil in a cleaner and more economical way, gasification has been developed and used worldwide, which converts the solid fuel or the high viscose bunker oil into syngas and the organic sulfur in it to $\mathrm{H}_{2} \mathrm{~S}$ [5-10]. The $\mathrm{H}_{2} \mathrm{~S}$ gas is highly toxic and often converted into elemental sulfur through the process on an industrial scale, referred as the Claus process [11-16]. The acid gas stream, consisting mostly of hydrogen sulfide, together with a controlled stoichiometric quantity of air is then fed to a furnace so that one-third of the hydrogen sulfide is burned to sulfur dioxide. The 
hydrogen sulfide and sulfur dioxide are next reacted together at elevated temperature in the gas phase to generate elemental sulfur and a tail gas $[12-15,17,18]$. The elemental sulfur is then recovered for sale or disposal and the tail gas either vented or subject to further treatment.

Meanwhile, the infrastructure of coal gasification plant often requires a power plant and steam boiler to provide electricity and steam, where almost half amount of the gasified coal is combusted; therefore $\mathrm{SO}_{2}$ is generated and

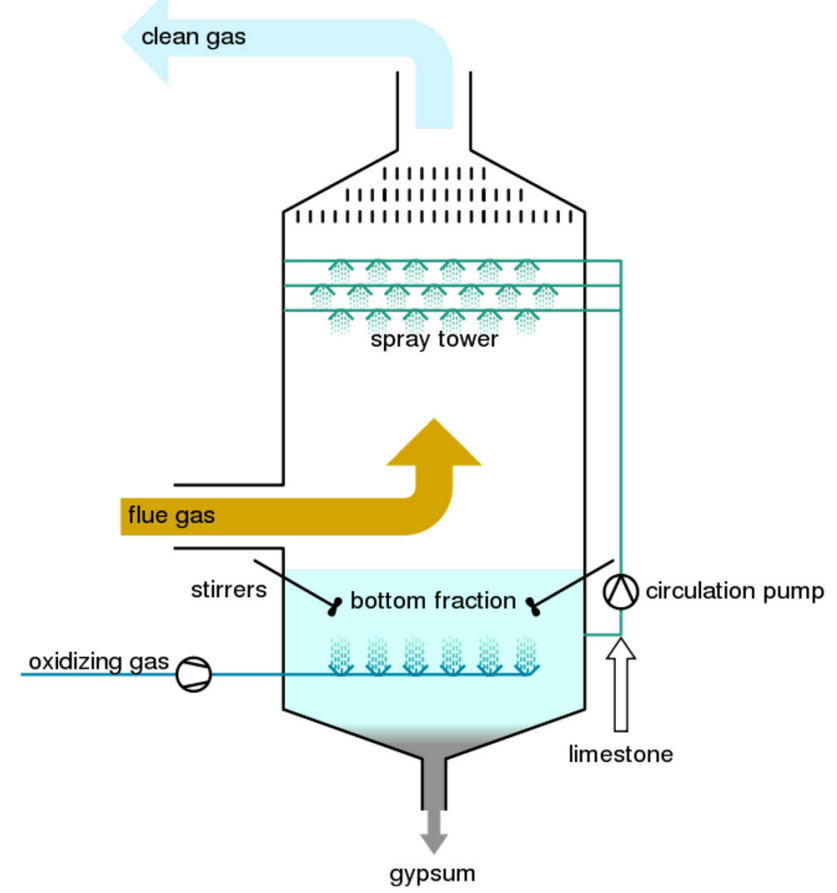

Fig. 1 The schematic setup of the flue gas desulfurization, adopted from: http://en.wikipedia.org/wiki/Flue-gas_desulfurization\#mediaviewer/ File:Flue_gas_desulfurization_unit_EN.svg must be removed from the flue gas before it is emitted to air. The removal of $\mathrm{SO}_{2}$ from flue gas is often through the lime water or dry lime powder treatment of the flue gas, the $\mathrm{SO}_{2}$ is converted into calcium sulfate, e.g., gypsum. Figure 1 gives a typical configuration of desulfurization of flue gas, where the lime water is spayed to the up-flowing flue gas, and the sulfur dioxide reacts with the lime in the lime water to give calcium sulfate, the gypsum precipitation.

It is known that the Claus process is mainly based on the reaction of $\mathrm{H}_{2} \mathrm{~S}$ with $\mathrm{SO}_{2}$ to give sulfur powder and water, which can be expressed by the following chemical reaction:

$2 \mathrm{H}_{2} \mathrm{~S}==2 \mathrm{H}_{2} \mathrm{O}+3 \mathrm{~S}$

$\mathrm{H}_{2} \mathrm{~S}_{2} \mathrm{O}_{5}+4 \mathrm{H}_{2} \mathrm{~S}===6 \mathrm{~S}+3 \mathrm{H}_{2} \mathrm{O}$

$\mathrm{H}_{2} \mathrm{SO}_{3}+2 \mathrm{H}_{2} \mathrm{~S}===3 \mathrm{~S}+3 \mathrm{H}_{2} \mathrm{O}$

In a heavy oil, petroleum coke, or coal gasification plant, there are $\mathrm{H}_{2} \mathrm{~S}$ separated from the gasified gas stream [1924], and also $\mathrm{SO}_{2}$ from the flue gas from coal combustion for power generation. Therefore, it is possible to make use of $\mathrm{H}_{2} \mathrm{~S}$ to react with $\mathrm{SO}_{2}$ without burning the $\mathrm{H}_{2} \mathrm{~S}$ to generate $\mathrm{SO}_{2}$. However, so far, there has been no such kind of study. In this work, we firstly introduced the separated $\mathrm{H}_{2} \mathrm{~S}$ gas into the flue, and replaced the lime water with an aqueous catalyst system to wash the flue gas containing $\mathrm{H}_{2} \mathrm{~S}$, a complete sulfur removal and also sulfur powder recovery process has been developed.

\section{The process principle consideration}

The flue gas stream containing $\mathrm{SO}_{2}$ is mixed with the $\mathrm{H}_{2} \mathrm{~S}$ feeding gas separated from the syngas stream, which should be fully mixed in the flue gas stream. The two
Fig. 2 The relationship between redox potential (E) and $\mathrm{pH}$ of hydrogen sulfide and sulfur dioxide in liquid phase under the condition of room temperature $\left(25^{\circ} \mathrm{C}\right)$ and normal pressure. This is calculated according to the thermodynamic method, as shown in http:// www.slideshare.net/ RafaelArdila1/atlas-eh-ph

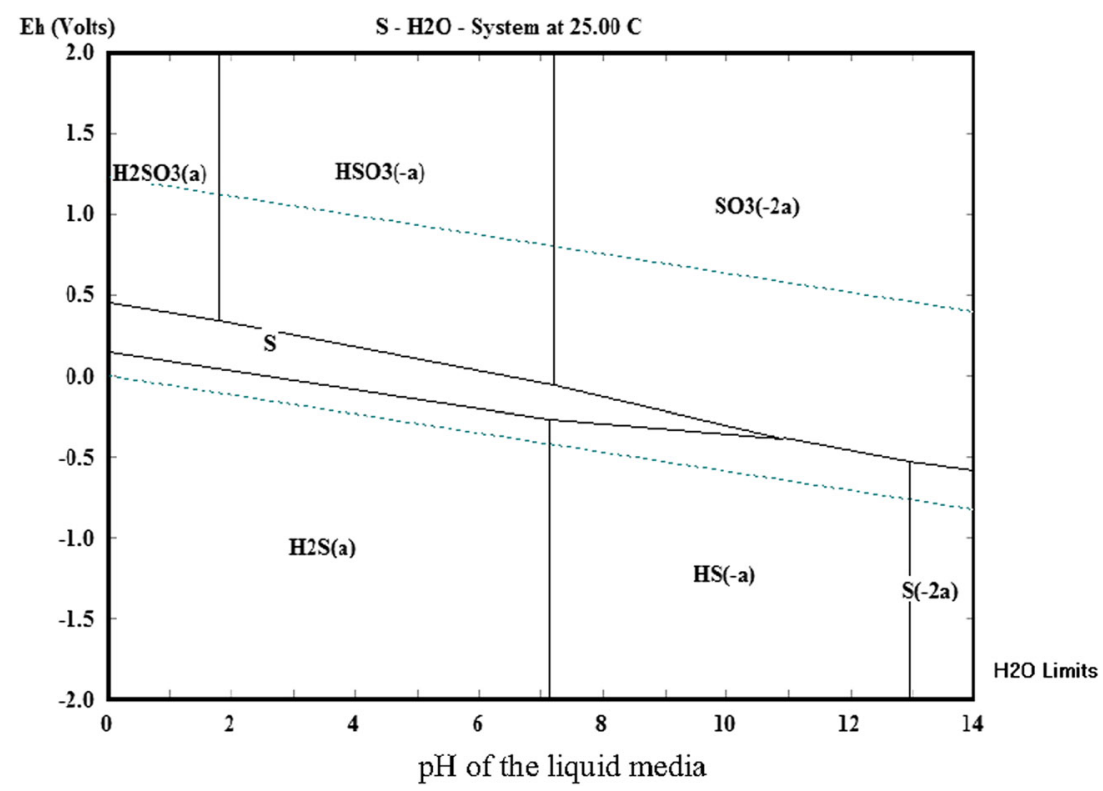


reactants would interact with the aqueous catalyst containing liquid media, and the sulfur dioxide would form various species such as $\mathrm{S}_{2} \mathrm{O}_{5}{ }^{2-}$ or $\mathrm{HSO}_{3}{ }^{-}$which would further react with $\mathrm{H}_{2} \mathrm{~S}$ to give elemental sulfur, as shown in reactions of 2 and 3 .

As shown in Fig. 2, the redox potential of $\mathrm{H}_{2} \mathrm{~S}$ reaction with $\mathrm{SO}_{2}$ in the aqueous system to give sulfur occurs at the $\mathrm{pH}$ of $0-10$, and the sulfur content gradually disappears with the increase of $\mathrm{pH}$. However, to contain both $\mathrm{SO}_{2}$ and $\mathrm{H}_{2} \mathrm{~S}$ in the aqueous system, the redox potential range should be from 0.2 to 0.5 . As we know, Eh is a measure of the redox (oxidation-reduction) state of a solution. As shown in Fig. 2, the drive for the elemental sulfur formation is $0.3-0.5 \mathrm{~V}$ in the reaction system, and the redox

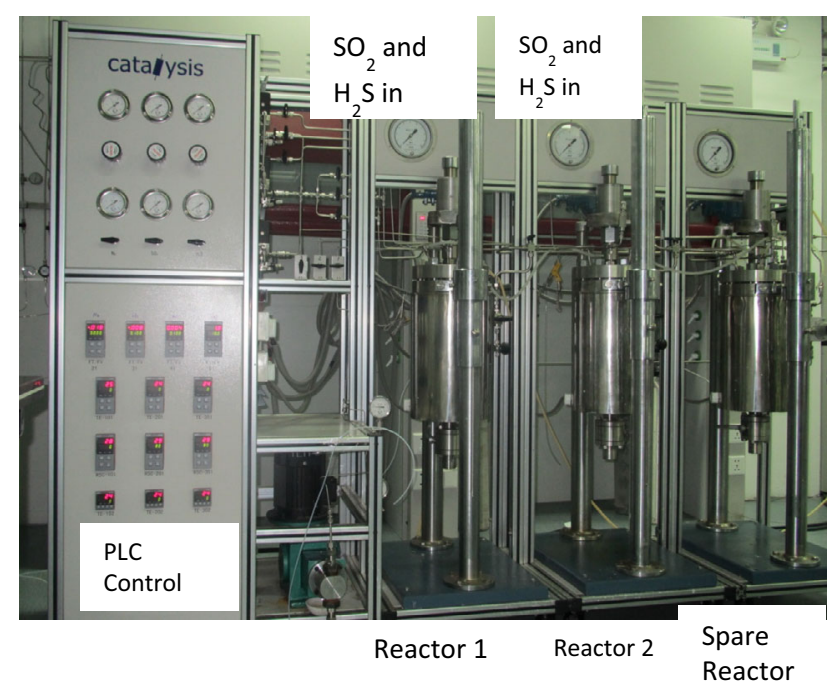

Fig. 3 The setup of the ambient temperature aqueous phase sulfur recovery test system potential decreases with the increase of $\mathrm{pH}$, which is preferably below 7.0 for the high Eh.

\section{Experimental}

The sulfur recovery experimental was carried out in a lab scale micro-reactor system; the image of the setup is shown in Fig. 3.

The system can operate at temperature from room temperature to $200{ }^{\circ} \mathrm{C}$ and the pressure can range from 1 to 20 bars. The gas flow is controlled by gas flowing meter. The $\mathrm{SO}_{2}$ content in $\mathrm{N}_{2}$ or mimic flue gas is about $200-1000 \mathrm{ppm}$, and the $\mathrm{H}_{2} \mathrm{~S}$ is fed separately from another gas stream, which is controlled to be 1.8-2.2 times (vol.) of the $\mathrm{SO}_{2}$. The reaction pressure is often carried out at ambient pressure.

\section{The chemicals and analysis system}

All the chemicals are industrial grade and supplied by Guangzhou Xinhe Standard Gas Company and China National Chemical Agent Company. Sulfur compounds in the gas stream are analyzed using temperature programmed gas chromatographic procedure employing a fused silica capillary column connected to a flame photometric detector (FPD). The FPD has a high selectivity to sulfur compounds compared to other non-sulfur gases. The sample collection loop was connected micro sampling valve which was plumbed into the carrier gas line.

The contents of the loop were transferred to the head of the capillary column where the sulfur compounds were focused in a narrow band, cryogenically. The detection limit with this system was approximately $1 \mathrm{ppm}$ (wt.) S.
Fig. 4 Schematic setup of the industrial process of the aqueous phase sulfur recovery system-the desulfurization unit, where the reaction of $\mathrm{SO}_{2}$ and $\mathrm{H}_{2} \mathrm{~S}$ occurs at three stages with acid aqueous catalyst washing media

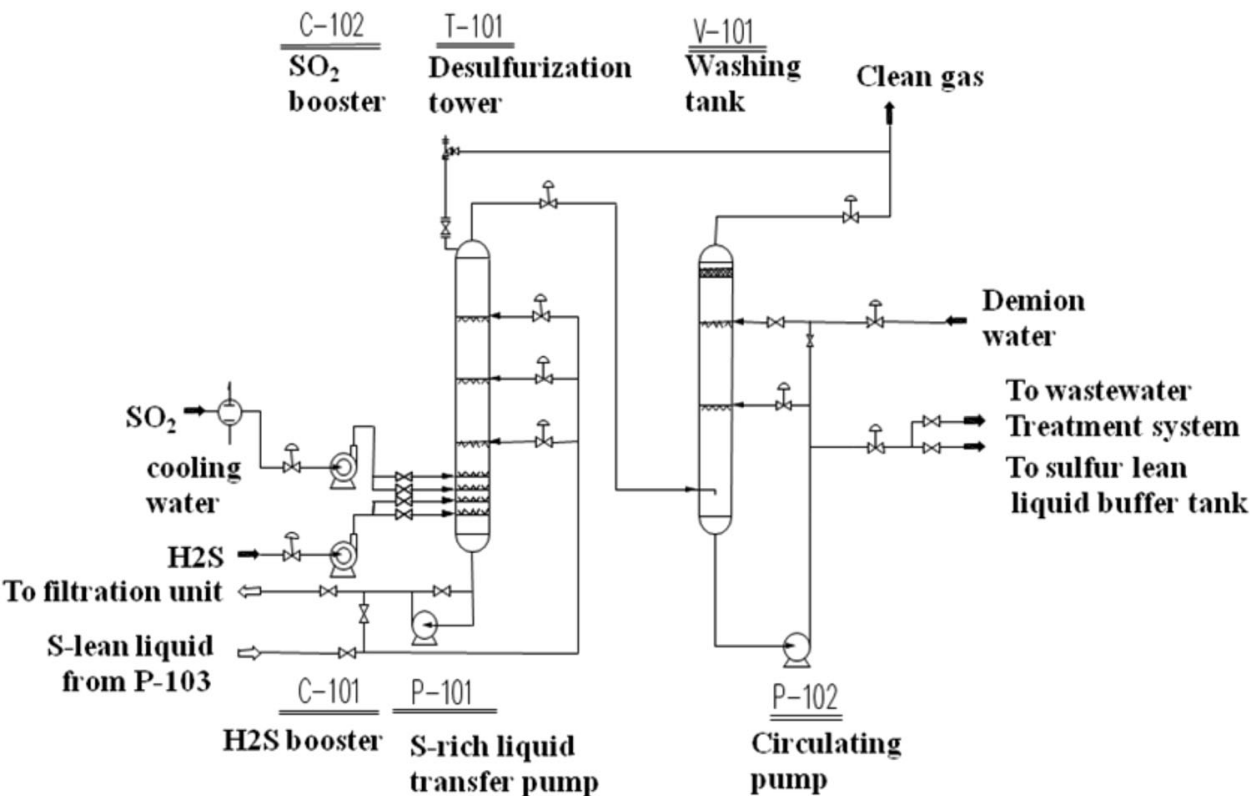

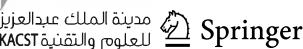




\section{Characterization of the sulfur powder}

The crystalline structure and phase component of the resulting sulfur powder were determined using X-ray diffraction with a Philips X' PeRT Pro Alpha 1 diffractometer with $\mathrm{Cu} \mathrm{K} \alpha$ radiation $(\lambda=1.5406 \AA)$ operated at a tube current of $40 \mathrm{~mA}$ and a voltage of $40 \mathrm{kV}$. Data were collected over $2 \theta$ values from $20^{\circ}$ to $70^{\circ}$, at a scan speed of $2^{\circ} \min ^{-1}$. The Laser Raman spectra of the sulfur sample were recorded using a Perkin Elmer 400F Ramanstation Raman spectrometer, with the sulfur powder.

\section{Industrial operation flow diagram and operation unit}

The technological process of the liquid-phase desulfurization process is showed in Figs. 4 and 5. The whole aqueous phase sulfur recovery technology composes of desulfurization unit (Fig. 4) and filtering unit (Fig. 5).

The desulfurization system mainly includes desulfurizing reaction tower (T-101) and washing tower $(\mathrm{V}-101)$. After passing the supercharger (C-101), the gas containing $\mathrm{H}_{2} \mathrm{~S}$ and flue gas from outside of the device enters the tower from the bottom of the desulfurizing reaction tower. At same time, the mixed liquor containing sulfuric acid catalyst enters the tower from the top of the tower. The gas and the liquid contact adequately, then the $\mathrm{H}_{2} \mathrm{~S}$ will be absorbed and then react with $\mathrm{SO}_{2}$ in the flue gas stream in the acid catalyst system. Elemental sulfur is generated along with the reaction. All the $\mathrm{H}_{2} \mathrm{~S}$ gas almost completely converts into elemental sulfur when passing through from the tower bottom to tower top.

After the desulfurization unit, the gas enters the washing tank from the top of the tower, the washing process can absorb the left residual $\mathrm{H}_{2} \mathrm{~S}$ and $\mathrm{SO}_{2}$ into the liquid phase so as to ensure this process can achieve deep desulfurization. Thereby the clean gas is obtained. Moreover, the mixed liquor of desulfurizing reaction tower enriches the elemental sulfur constantly and is discharged from the tower bottom to some extent. Then it is transferred to the filtration system by the sulfur rich liquid bump (P-101).

The filtering system includes double bag filter (F-101A/ B), poor liquid buffer tank (V-102) and pneumatic diaphragm additive pump (P-104). The elemental sulfur is separated and the liquid is recycled after the rich liquid sulfur getting through the double bag filter. The filtrate will enter the poor liquid buffer tank. The mixed liquor containing soluble catalyst is replenished by pneumatic diaphragm additive pump. The filter liquor after sulfuric acid catalyst top-up will re-enter the desulfurizing reaction tower by using the sulfur-poor liquid pump and re-used in a closed loop.

By using this liquid-phase desulfurization process at room temperature under atmospheric pressure, we achieved deep desulfurization in the gas that containing $\mathrm{H}_{2} \mathrm{~S}$ and $\mathrm{SO}_{2}$ in the flue gas and the sulfur concentration in tail gas is reduced to $<50 \mathrm{ppm}$, this is due to that the low temperature operation overcomes the thermodynamic restricts of the reaction 1 , which is strong exothermic reaction, the $\Delta \mathrm{H}$ is $233.6 \mathrm{~kJ} / \mathrm{mol}$ of $\mathrm{SO}_{2}$. Thus aqueous phase operation can help the heat transfer and control the reaction to occur at
Fig. 5 The schematic diagram of the sulfur powder filtration unit

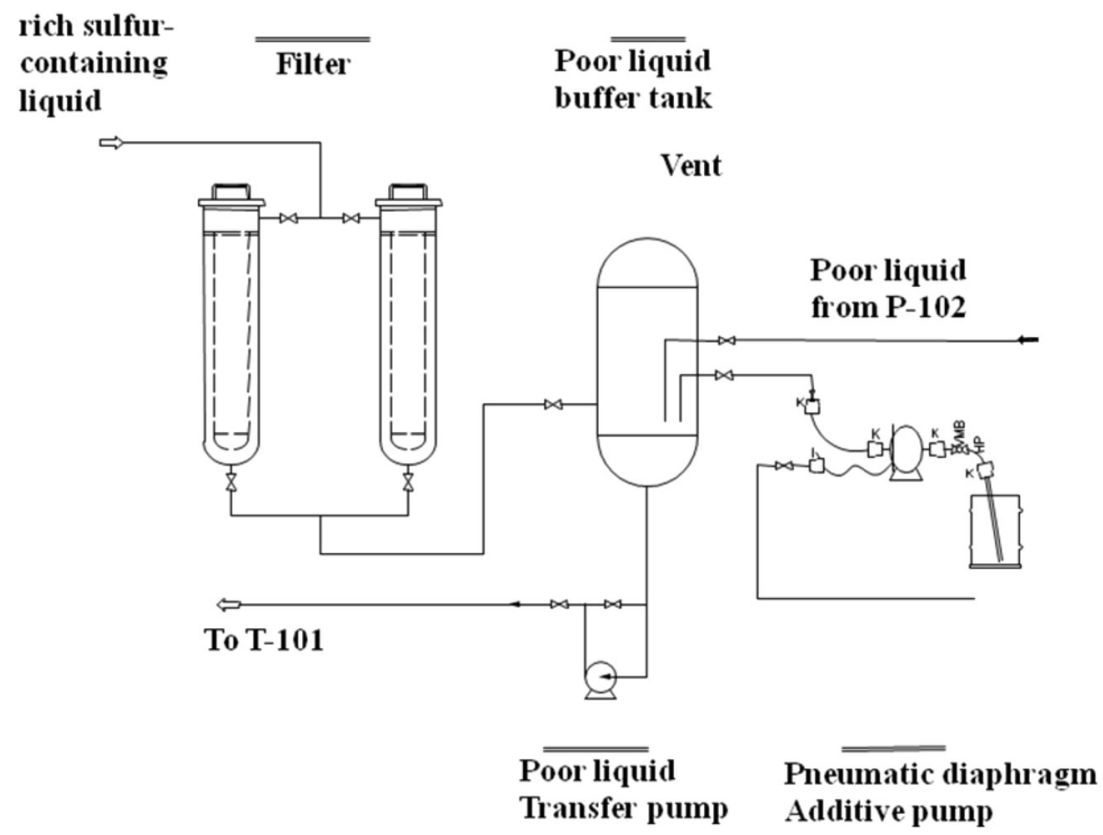


low temperature. It also produces highly pure elemental sulfur powder, which contains little insoluble impurities like alumina or iron or the embedded hydrogen sulfide gas, in contrast to the high temperature Claus process $[12,17]$. This sulfur powder product is valuable for chemical and agricultural use.

\section{Industrial side stream test results}

A side stream test of the aqueous phase ambient temperature sulfur recovery technology has been set up in Gansu Huating Coal Conversion Company according to the design shown in Figs. 4 and 5. The flue gas was from the steam boiler, containing $500-520 \mathrm{ppm}$ of sulfur after dust removal. The diverted gas flowing rate to the reactor was $60 \mathrm{nM}^{3} / \mathrm{h}$, and $\mathrm{H}_{2} \mathrm{~S}$ separated from the gasified gas stream has purity of 60-80 vol \% balanced with $\mathrm{N}_{2}$, which was fed into the flue gas at $\mathrm{H}_{2} \mathrm{~S}: \mathrm{SO}_{2}$ volume ratio of 1.8-2.1:1. The

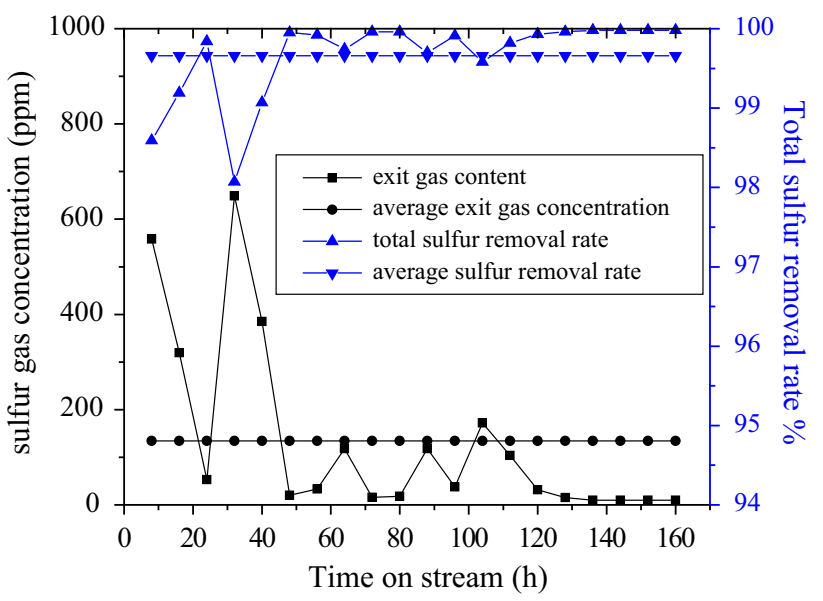

Fig. 6 The sulfur removal efficiency with the time on stream in the flue gas and $\mathrm{H}_{2} \mathrm{~S}$ conversion, the operation conditions: feeding rate: $\mathrm{L}_{\text {flue gas }}=60 \mathrm{nM}^{3} / \mathrm{h}, \mathrm{H}_{2} \mathrm{~S}$ feeding concentration $800-1000 \mathrm{ppm}$; flue gas containing 500-520 ppm vol $\mathrm{SO}_{2}$ pressure: $\mathrm{R} 1$ : $0.14 \mathrm{MPa}$ flue gas temperature was about $200-300{ }^{\circ} \mathrm{C}$ and the acid catalyst solution media was sprayed to the up-flow gas at three stages and the sulfur rich solution temperature can be up to $70{ }^{\circ} \mathrm{C}$.

The change of the total sulfur concentration with the time on stream is shown in Fig. 6. The excess of $\mathrm{SO}_{2}$ in the gas stream is to ensure the complete conversion of $\mathrm{H}_{2} \mathrm{~S}$. There was no $\mathrm{H}_{2} \mathrm{~S}$ detected in the exit gas stream. As shown in Fig. 6, the total sulfur removal ratio varied from 98 to $100 \%$, but the overall average sulfur removal ratio is more than $99.6 \%$, and the exit sulfur content varied from 10 to $600 \mathrm{ppm}$, which may be due to the adsorption-desorption in the sulfur saturated washing liquid. The overall average exit sulfur content as $\mathrm{SO}_{2}$ is about 150-170 weight ppm, which can meet the emission regulations. The system tends to be stable with the time on stream and after $160 \mathrm{~h}$ of time on stream, the sulfur removal efficiency and also the exit sulfur concentration all stable, not decay in the $160 \mathrm{~h}$ operation.

Sulfur often easily forms colloid in water solution, and the separation of sulfur from water is difficult in many cases. To develop the way to separate the sulfur from the aqueous phase catalyst system, we have taken $1000 \mathrm{ml}$ of the sulfur rich catalyst solution and left it in the beaker statically in air (as shown in Fig. 7). It is shown that after $1 \mathrm{~h}$ placement, the sulfur powder settle down to the bottom of the beaker, which can be separated easily through decanting the top water layer. This suggests that the sulfur could be easily filtered from the aqueous phase catalyst system. This also lays the foundation for the elemental sulfur filtration technology development.

The sulfur powders from the aqueous phase catalyst system and also from the high temperature Claus process have been collected and characterized using laser Raman, the results are shown in Fig. 8. It is shown that there are four main distinct Raman bands seen in all the samples, corresponding to the frequencies of $82,154,218$, and $474 \mathrm{~cm}^{-1}$. The bands at the frequencies $82,154,218$, and
Fig. 7 The images of the sulfur containing aqueous catalyst media and after settling down; a the as-received sulfur-catalyst liquid solution, $\mathbf{b}$ after $1 \mathrm{~h}$ setting down
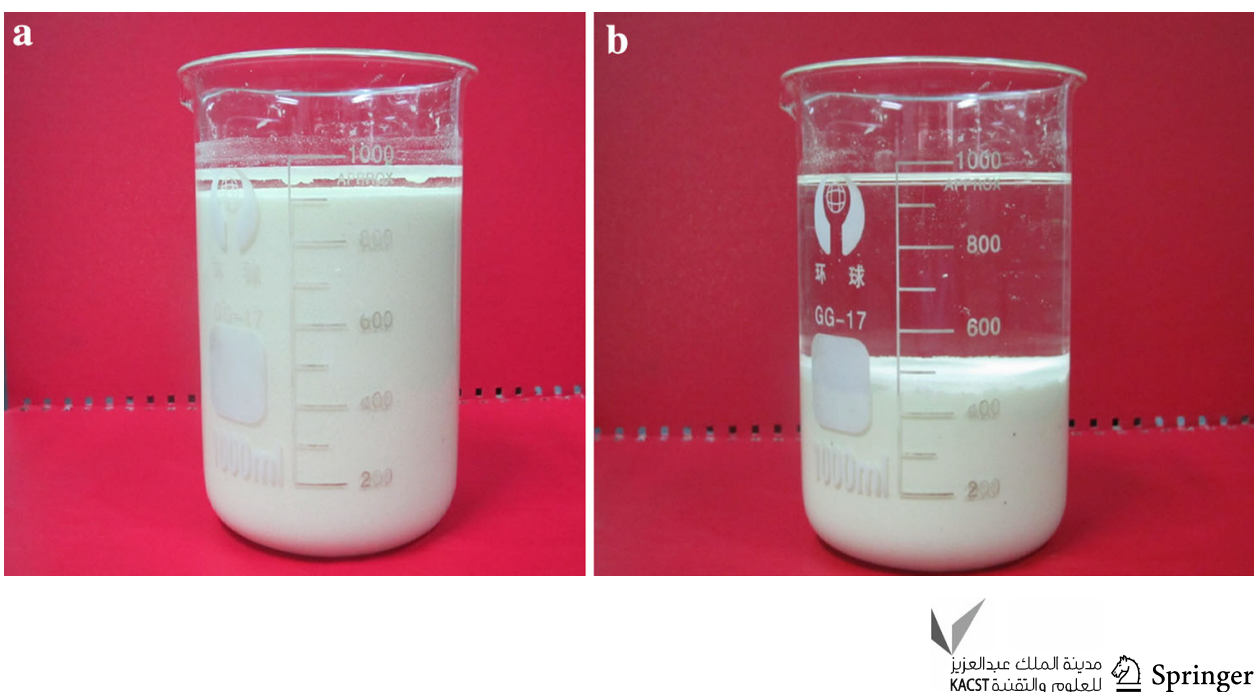


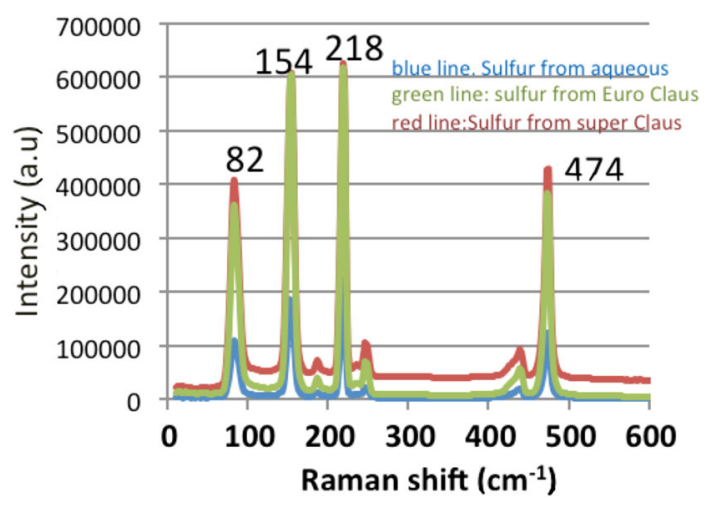

Fig. 8 Laser Raman spectra of the recovered sulfur products from various sulfur recovering technologies

$474 \mathrm{~cm}^{-1}$ correspond to the internal modes of the crownlike $\mathrm{S}_{8}$ ring and we ascribed them to the $\mathrm{E} 2$ torsion mode, E2 bond-bending mode, A1, bond-bending mode and A1, bond-stretching mode of the $S_{8}$ ring, respectively $[25,26]$. The strongest Raman band at $480 \mathrm{~cm}^{-1}$ has two shoulders. The shoulder on the low-frequency side of the band is assigned to the E2 bond-stretching mode of $S_{8}$.

The Raman bands of the sulfur from the aqueous phase ambient temperature system are identical to the Raman spectrum of the sulfur from high temperature Claus process, suggesting that the sulfur has similar structure. No other Raman bands are seen in the sulfur sample from aqueous catalyst system, suggesting its surface has no Laser Raman detectable impurities.

\section{Conclusion}

1. Aqueous phase ambient temperature sulfur recovery has been developed and tested in side stream of a coal gasification plant; it can convert $\mathrm{H}_{2} \mathrm{~S}$ from the gasified syngas and $\mathrm{SO}_{2}$ in the flue gas into sulfur powder through a 3-stage acid solution washing techniques. This enables a complete reaction of $\mathrm{H}_{2} \mathrm{~S}$ and $\mathrm{SO}_{2}$ to convert into sulfur powder, which makes it possible to fully recover the sulfur from coal gasification.

2. Aqueous phase reaction helps the heat transfer and enables the reaction to occur at lower temperature $\left(<100{ }^{\circ} \mathrm{C}\right)$. The sulfur formation in the aqueous phase has big aggregate, which can easily settle down to the aqueous bottom and can be separated from the catalyst through filtration.

3. The recovered sulfur has high purity and similar purity as the one from high temperature Claus process. The simultaneously removing $\mathrm{H}_{2} \mathrm{~S}$ and $\mathrm{SO}_{2}$ from the gas streams makes it possible to purify the flue gas and $\mathrm{H}_{2} \mathrm{~S}$ process gases in one unit, which would save significant capital and operation cost.
Acknowledgments We would like to thank Huating Coal Conversion Plant for their help in running the side stream test of the technology in their plant. Great thanks are due to Guangdong Provincial Science Parks Hi-Tech Program (Project No: 2012B010900045).

Open Access This article is distributed under the terms of the Creative Commons Attribution 4.0 International License (http:// creativecommons.org/licenses/by/4.0/), which permits unrestricted use, distribution, and reproduction in any medium, provided you give appropriate credit to the original author(s) and the source, provide a link to the Creative Commons license, and indicate if changes were made.

\section{References}

1. Nuhu AA (2013) Bio-catalytic desulfurization of fossil fuels: a mini review. Rev Environ Sci Bio/Technol 12(1):9-23

2. Shah SN (2014) Sulfur compounds significance in fossil fuels and their impact on the environment. Adv Chem Res 22:203-216

3. Srinivasan $T$ et al (2014) Environment threat: impact on acid rain formation on soil. Pollut Res 33(1):191-193

4. Yuan X et al (2013) Strategic route map of sulfur dioxide reduction in China. Energy Policy 60:844-851

5. Anderson GL, Hill AH, Fleming DK (1979) Environmental quality and energy conservation in coal conversion processes. Energy Environ 6:346-353

6. Netzer D (1979) Fuel gas by Fluor-combination coal gasification. Coal Technol (Houston) 2nd(3):93-111

7. Stasa FL, Osterle F (1981) The thermodynamic performance of two combined cycle power plants integrated with two coal gasification systems. J Eng Power 103(3):572-581

8. Fermoso J et al (2010) Co-gasification of different rank coals with biomass and petroleum coke in a high-pressure reactor for H2rich gas production. Bioresour Technol 101(9):3230-3235

9. Marin-Sanchez JE, Rodriguez-Toral MA (2011) Model for gasification of residual fuels from petroleum refineries using the equation oriented (EO) approach. Ind Eng Chem Res 50(5):2628-2640

10. Murthy BN et al (2014) Petroleum coke gasification: a review. Can J Chem Eng 92(3):441-468

11. Barnhart JH (1978) Energy analysis of a Claus plant. Chem Eng Prog 74(5):58-59

12. George ZM (1978) Poisoning and regeneration of Claus alumina catalysts. Can J Chem Eng 56(6):711-715

13. Hicks M (1999) Improved Claus SRU control and emissions tracking using PLC control. In: Proc-Laurance Reid gas cond conf, pp 199-229

14. Li J, Huang L, He J (2014) The study of the influence of sulfur on the catalyst structure in low temperature Claus processes. Adv Mater Res (Durnten-Zurich, Switz) (Biotechnology, Chemical and Materials Engineering III) 884-885:182-185

15. Li Q et al (2013) Economics of acid gas injection with comparison to sulfur recovery in China. Energy Procedia $37: 2505-2510$

16. Sinha $\mathrm{S}$ et al (2014) Toluene destruction in the Claus process by sulfur dioxide: a reaction kinetics study. Ind Eng Chem Res 53(42):16293-16308

17. McHugh T, Luinstra E (1998) The Claus sulfur recovery process. Int J Hydrocarbon Eng 3(9):47-48 (50-52)

18. Savin $\mathrm{S}$ et al (1998) New developments in sulfur recovery process technology. Int J Hydrocarbon Eng 3(4):54-56

19. Alexander SR, Winnick J (1994) Electrochemical polishing of hydrogen sulfide from coal synthesis gas. J Appl Electrochem 24(11):1092-1101 
20. Cormos C-C (2014) Techno-economic and environmental evaluations of large scale gasification-based CCS project in Romania. Int J Hydrogen Energy 39(1):13-27

21. Ma X, Wang X, Song C (2009) "Molecular basket" sorbents for separation of $\mathrm{CO}_{2}$ and $\mathrm{H}_{2} \mathrm{~S}$ from various gas streams. $\mathrm{J}$ Am Chem Soc 131(16):5777-5783

22. Niswander RH et al (1993) A more energy efficient product for carbon dioxide separation. Sep Sci Technol 28(1-3):565-578

23. Rolker J, Lenormant T, Seiler M (2012) A new chemical system solution for acid gas removal. Chem Ing Tech 84(6):849-858
24. Shannon MS et al (2012) Evaluation of alkylimidazoles as physical solvents for $\mathrm{CO}_{2} / \mathrm{CH}_{4}$ separation. Ind Eng Chem Res 51(1):515-522

25. Anderson A, Loh YT (1969) Low temperature Raman spectrum of rhombic sulfur. Can J Chem 47(6):879-884

26. Poborchii VV (1998) Raman spectra of sulfur, selenium or tellurium clusters confined in nano-cavities of zeolite A. Solid State Commun 107(9):513-518 